\title{
Spatial Firing Properties of Hippocampal Theta Cells
}

\author{
John L. Kubie, Robert U. Muller, and Elizabeth Bostock \\ Departments of Anatomy and Cell Biology and Physiology, SUNY Health Sciences Center at Brooklyn, Brooklyn. \\ New York 11203
}

\begin{abstract}
Previous studies have shown that complex-spike cells, the most common cell type recorded in the hippocampus of freely moving rats, have the property of spatial firing-that is, a cell will fire rapidly only when the animal is in a particular part of its environment (O'Keefe and Dostrovsky, 1971). In the current study, we analyze the spatial firing of theta cells, the second major class of cells in the hippocampus, which are thought to correspond to nonpyramidal neurons (Fox and Ranck, 1975, 1981). Our purposes were to extend findings from earlier spatial analyses (McNaughton et al., 1983; Christian and Deadwyler, 1986), and to determine whether the spatial firing is cell specific and independent of behavior.

Theta cells were recorded from rats in a cylindrical enclosure using techniques previously used for the analysis of spatial firing in complex-spike cells (Muller et al., 1987). The spatial firing patterns of individual neurons appeared as a complex surface with several regions of high and low firing. The ratio of firing from high- to low-rate regions averaged 2.5. These spatial firing patterns were smooth and reproducible, but less so than for complex-spike cells. When a cue card on the wall was moved, theta cell firing patterns remained in register with the cue. Two analyses were performed to determine whether spatial firing patterns were secondary to spatial distributions of behavior. When only locomotor data segments were selected, spatial variations were more clear-cut. In an attempt to test whether theta cells had cell-specific patterns of firing, pairs of theta cells were recorded simultaneously. On all occasions, the firing distribution for each of the cells in a pair was clearly distinctive. These findings support the conclusions that theta cell activity contains a spatial signal that is cell specific and not secondary to other firing correlates.
\end{abstract}

On the basis of several criteria, hippocampal neurons can be divided into "complex-spike" and "theta" cells (Ranck, 1973). When complex-spike cells are recorded from freely moving rats, most fire rapidly only when the rat is in a particular part of its environment (O'Keefe and Dostrovsky, 1971; O'Keefe, 1976 , 1979; Olton et al., 1978; Best and Ranck, 1982). Complex-spike cells that fire in this "location-specific" fashion are named "place"

\footnotetext{
Received June 20, 1989; accepted Aug. 9, 1989.

This work was supported by NIH grant NS 20686 to J.L.K. and R.U.M. We are indebted to Ms. Leslie Kramer for assistance in carrying out these studies. We thank Drs. James B. Ranck and Steven E. Fox for help, assistance, and many useful discussions.

Correspondence should be addressed to Dr. John L. Kubie, Department of Anatomy and Cell Biology, Box 5, SUNY Health Sciences Center at Brooklyn, 450 Clarkson Ave., Brooklyn, NY 11203.

Copyright (C) 1990 Society for Neuroscience $0270-6474 / 90 / 041110-14 \$ 02.00 / 0$
}

cells (O'Keefe and Conway, 1978); the regions of intense activity are called "firing fields" (Muller et al., 1987). By contrast, it has generally been reported that theta cells do not exhibit locationspecific firing (Ranck, 1973; O'Keefe and Nadel, 1978; Christian and Deadwyler, 1986). Instead, their firing has been described as correlated with locomotor activities such as walking, running, or jumping, independent of the animal's position during locomotion. Ranck (1973) found that the firing rate of theta cells increased whencver the rat moved. In agreement, O'Keefe and Nadel (1978) called theta cells "displace cells" to emphasize the strong relationship between firing and movement. Christian and Deadwyler (1986) reported that theta cell firing changes during the acquisition of a conditioned reflex, but denied the presence of spatial firing. Most previous work, therefore, suggests that theta cell activity is behavior-specific rather than location-specific, and that all theta cells have similar, if not identical, behavioral correlates. It is important to note that McNaughton et al. (1983) reported a weak, but detectable relationship between theta cell firing and the rat's location, since their findings partially anticipate our results.

An alternative hypothesis about theta cell firing arises from the widely held belief that theta cells are interneurons or nonpyramidal units, whereas complex-spike cells (place cells) are pyramidal neurons (Fox and Ranck, 1975, 1981). The connectivity of interneurons and pyramidal cells suggests that each theta cell receives excitatory input from many complex-spike cells (Knowles and Schwartzkroin, 1981). From the strong location-specific firing of complex-spike cells, it is therefore plausible that each theta cell might have its own characteristic spatial firing pattern. If the degree of convergence of pyramidal cells onto interneurons is not very large, it might be expected that a given theta cell would have several regions of high activity, where each region would correspond to the firing field of an afferent complex-spike cell.

A major purpose of this study was to record from hippocampal theta cells to determine whether we could discern systematic spatial firing patterns, as earlier work disagreed on this issue (McNaughton et al., 1983; Christian and Deadwyler, 1986). Our strategy was to record from a theta cell while the rat ran over the entire surface of a cylindrical enclosure. We found that theta cell firing was clearly correlated with the rat's position in the cylinder, in general agreement with the findings of McNaughton et al. (1983), although the strength of the spatial signal reported here appears to be greater. After we had shown that theta cell firing varies with the animal's location, it was possible to make quantitative comparisons between the spatial firing of theta cells and complex-spike cells.

Establishing a correlation between theta cell firing and the rat's location is not a sufficient demonstration that location is 
a critical variable. It could be that spatial firing correlates are secondary to the rat's propensity to perform certain behaviors in certain locations. A second major purpose of this study was to test the hypothesis that theta cell firing is exclusively correlated with behavior and that spatial firing variations are incidental. McNaughton et al. (1983) provided evidence against this notion on the basis that small firing variations could be seen from arm to arm on an 8-arm maze. The variations occurred despite the fact that similar behavior is expected at corresponding points on arms of the maze. As these authors noted, however, the low partial correlation of firing and position could still arise from details in the tendency of the rat to do certain things on different arms. This is a general problem in any attempt to show a behavior-independent component of spatial firing. The existence of such a behavior-independent component can never be proved, but gains credence as the most likely behavioral sources of firing modulation are eliminated.

Two methods were used to address this issue. First, a task was chosen that restricted the range of behaviors exhibited by the rats during recording sessions. Rats were trained to chase food pellets scattered into the recording chamber throughout testing sessions. They spent about $80 \%$ of their time walking around the apparatus. Eating and still-alert behavior occupied the remaining $20 \%$ of the typical session. Other behaviors, such as grooming or standing, are extremely infrequent and take up only a small percent of the rat's time. To a first approximation, therefore, the question of whether behavioral correlates of theta cell firing indirectly produce spatial firing patterns is reduced to the question of whether spatial firing is secondary to the rat's tendency to walk through certain regions of the apparatus and rest in others. This possibility arises from the fact that theta cell firing is faster during walking than during quiet alertness (Ranck, 1973).

Three analytic techniques were used to test whether the spatial firing variations of theta cells were entirely secondary to differential distributions of walking and resting. The first 2 methods tested whether spatial firing variations were eliminated when firing during restricted locomotor states is considered. In the first method, segments of recording sessions were sorted into 2 classes, based on whether the rat's average speed over a fixed interval was greater or less than a selected value. If the spatial firing variations persisted or were enhanced when only highvelocity (walking) or lower-velocity (resting) segments were considered, it would be clear that the motion/rest dichotomy could not account for spatial firing. In the second method, regions of high and low firing were identified from color-coded firing rate maps (Muller et al., 1987), and sets of trajectories were selected when the rat was walking or stationary in each region. Again, if firing rate differences persisted during the trajectories of a particular behavior, the notion that firing was partially independent of the rat's behavior would be supported. Finally, in a different vein, we investigated the extent to which the spatial firing patterns of simultaneously recorded cells resembled each other. If a single behavioral firing correlate existed for both cells and this correlate determined spatial firing, then the spatial firing patterns for the 2 cells of the pair should be nearly identical. Conversely, if different spatial firing patterns were seen for the 2 cells, cell specificity will have been established.

It is important to state that our analysis was not aimed at disproving the well-known and easily observed correlation of behavior with theta cell firing. Our intentions were instead to measure the strength of spatial variations in theta cell firing, and to show that these variations are not solely due to differential distributions of behavior.

\section{Materials and Methods}

The methods for measuring the spatial firing patterns of hippocampal neurons were described in a previous paper (Muller et al., 1987). Some of the essentials are repeated here, but the cited paper should be consulted for details. This section is mainly concerned with our methods for ensuring that we were recording from single theta cells, and with analytic methods of describing theta cell firing patterns.

Apparatus. The recording chamber was a $76-\mathrm{cm}$-diameter, $51-\mathrm{cm}-$ high cylinder. The inner wall of the cylinder was gray and $100^{\circ}$ of the surface of the wall were covered with a white stimulus card. The chamber had no floor, but was laid on replaceable gray photo backdrop papcr. Outside was a circular curtain $213 \mathrm{~cm}$ in diameter and $213 \mathrm{~cm}$ high. Illumination was provided by $415-\mathrm{W}$ light bulbs symmetrically arranged overhead.

Behavioral training. Rats were pretrained in the cylinder to chase 20mg food pellets (BioServe, Frenchtown, NJ) which were thrown on the floor paper of the apparatus. With half an hour's training per day for 2 weeks, rats readily learned to orient toward and retrieve the pellets. At the end of training, a rat's activity consisted mainly of walking or running (locomotion). Rats spent the remainder of the time stationary, some of which was coincident with eating. Other activities, such as grooming, were extremely infrequent.

Electrode implantation and unit screening. After training, a drivable bundle of 10 microelectrodes was implanted (Kubie, 1984). The electrodes were made of formvar-insulated, $25-\mu \mathrm{m}$-diameter nichrome cut square at the tips. The bundle was implanted so that the longest wire was several hundred microns above the CA 1 pyramidal cell layer of the dorsal hippocampus, and in a medial-lateral plane that crosses part of the upper blade of the dentate gyrus and the CA3 pyramidal cell layer. Advancing the electrode permitted recordings from both CA1 and CA3. $A$ rat was allowed at least $3 \mathrm{~d}$ to recover from surgery before unit screening was initiated.

During screening, the rat was placed in the cylinder, and the recording cable was attached to the electrode assembly. The rat end of the cable contained field-effect transistors configured as source followers; the other end went to a commutator. Signals from the microelectrodes were amplified (2000 times) and bandpass-filtered $(300-10,000 \mathrm{~Hz})$. The signal was displayed on an oscilloscope and discriminated with an analog delay linc and a scrics of 3 time/amplitude window discriminators (Bak DIS1 , Rockville, MD). The acceptance pulses of the third discriminator were counted as spikes. When 2 theta cells were simultaneously available for study, a second set of amplifiers, filters, and window discriminators was used. The electrodes were screened several times a day with the rat in the small cylinder. If no useful action potential activity was found, the electrode bundle was advanced by $25-50 \mu \mathrm{m}$ and the rat was returned to its home cage for at least $1 \mathrm{hr}$. When a cell was found we attempted to establish that the firing was from a single theta cell and not a composite of the waveforms of several cells.

To demonstrate that the preponderance of waveforms were from a theta cell, several criteria had to be met. First, following Ranck (1973), the firing frequency had to increase whenever the rat's behavior switched from alert motionless or eating to locomotion. Second, the negative phasc of the waveform had to be between 150 and $300 \mu \mathrm{sec}$ in duration (Ranck, 1973). Third, the waveform amplitude was required to be constant; the candidate waveform was rejected if it ever showed complexspikes (a decrementing series of spikes at short intervals). Finally, the overall firing rate had to be at least 5 spikes/sec, well in excess of the grand average rate of place cells of about $1 / \mathrm{sec}$. Theta cells were encountered less frequently than complex-spike cells, but once found were usually easy to isolate. In addition, to be used in a formal recording session, the cell's waveform had to be stable for at least $30 \mathrm{~min}$, as determined with a storage oscilloscope.

The 4 stated criteria are enough to ensure that most of the waveforms were generated by a theta cell. Additional efforts were made to preclude the possibility that the time series was contaminated by spikes from a second theta cell or from one or more complex-spike cells. First, theta cells were never recorded when we felt the electrode was within the pyramidal cell layer of $\mathrm{CA} 1$ or $\mathrm{CA} 3$, the regions with most complexspike cells and most obvious multiple-unit activity. Most recordings were made when no competing cell waveforms were present. Second, the 3 time windows were very close together, so that only short-duration 
Table 1. Color codes for Figure 1

Median rate in each color category (spikes/sec):

\begin{tabular}{lcccccc}
\hline & & & & & & \multicolumn{2}{c}{$\begin{array}{l}\text { Mean } \\
\text { session } \\
\text { rate }\end{array}$} \\
\hline Complex-spike cell & 0.94 & 2.95 & 6.67 & 11.0 & 16.5 & 1.4 \\
Theta cell 1 & 21.6 & 29.6 & 34.9 & 41.0 & 50.2 & 29.5 \\
Theta cell 2 & 62.3 & 74.2 & 81.6 & 91.3 & 101.4 & 75.6 \\
Dwcll-timc map lower boundaries for each color (scc): & & & & \\
Complex-spike cell & 0.74 & 1.04 & 1.36 & 1.84 & 2.78 & \\
Theta cell 1 & 0.43 & 0.83 & 1.24 & 1.91 & 3.19 & \\
Theta cell 2 & 0.69 & 1.01 & 1.38 & 1.86 & 2.86 & \\
\hline
\end{tabular}

waveforms would be accepted and the relatively long-duration waveforms typical of complex-spike cells would be rejected. This is a strong criterion, since Ranck (1973) and Fox and Ranck (1981) showed that the spike duration distributions of theta cells and complex-spike cells do not overlap. Third, before each recording session, the discriminated spikes were used to trigger a storage oscilloscope for a 1-min interval. Recordings were not made unless the the $2-\mathrm{msec}$ interval following the triggers was free of spike waveforms. This procedure guarded against the possibility that the waveform time series consisted of the output of 2 theta cells that could not be discriminated from each other. A second theta cell would generate about 50 spikes in the 2 -msec interval with 1 min of sampling. (If both cells fired 20 action potentials per sec, there is a 1 in 25 chance that a spike from one theta cell will fall within 2 msec of a single spike from another; given 1200 spikes from one cell in a minute, the number of spikes from a second, independent cell would be about 50.) Since complex-spike cells fire at about 1 spike/sec, a complex-spike cell would generate about 2.4 spikes in the $2-\mathrm{msec}$ interval. Finally, we used the same dead-time analysis on tape records of the discriminator output for complete 16-min sessions from 7 cells. If the theta cell frequency is again assumed to be $20 \mathrm{spikes} / \mathrm{sec}$ and complex-spike cell frequency to be 1 spike/sec, about 40 events within the 2 -msec window would be expected. Since we saw only 5 such events in the worst case, we conclude that we were recording the output of single theta cells.

When an electrode pass was completed for a rat (after about 1-2 months of recording), a small electrolytic lesion was made through the longest wire. The rat was then killed with an overdose of pentobarbital followed by transcardial perfusion of saline and formal saline. The brain was removed and stored overnight in a formalin potassium ferrocyanide solution. Fifty-micron frozen sections of the brain were made through the hippocampus and the sections were Nissl-stained. From the location of the lesion, the position of the electrode during recording sessions was calculated.

Data collection technique. Recording sessions lasted $16 \mathrm{~min}$. The rat's task was to chase food pellets thrown to random parts of the cylinder by an experimenter who stood outside the curtained enclosure. Rats will chase food pellets almost continuously in this situation. Their behavior during a session thus consisted mainly of locomotion. For tracking, a pair of small incandescent bulbs was attached to the rear of the rat's headstage, approximately above each ear; 2 lights were used to decrease the likelihood that the recording cable would cause loss of detection. The output of an overhead videocamera was fed to a homemade spot detector which detected the $x$ and $y$ positions of the headlights with $64 \times 64$ resolution. Each small rectangular region (pixel) in the 64 $\times 64$ grid was $2.8(y)$ by $3.4(x) \mathrm{cm}$. The acceptance pulses from the window discriminators were fed to an accumulator that could count to 15 before saturation. When 2 cells were recorded simultaneously, the output of each set of discriminators was sent to an accumulator that could count to 3 before saturation. [Since theta cells have minimum interspike intervals of about $7 \mathrm{msec}$ (Ranck, 1973), they virtually never fire more than 3 action potentials in the $17 \mathrm{msec}$ between data samples.] Sixty times per second, the $y$ and $x$ position of the light bulbs, and the number of spikes for one or both cells were sent to the computer. These values were packed into a 2-byte data sample with 6 bits for $x, 6$ bits for $y$, and 4 bits for spikes. The data were stored and analyzed off-line.
During recording sessions, the TV signal was often recorded on a videocassette recorder. The discriminated spikes and EEG (FM modulated with a Vetter model 4) were recorded on the 2 audio channels of the VCR.

All theta cells were run in at least one standard session. A standard recording session lasted $16 \mathrm{~min}$ with the cue card centered at the 3:00 position as seen from the overhead camera. For most cells, at least one additional standard session was run. Many cells were also recorded while the cue card was rotated $90^{\circ}$ counterclockwise. Between all sessions the rat was returned to its home cage and the floor paper replaced; the usual session rate was about one per hour. Under these circumstances, 4 or 5 sessions could be run before the rat became satiated and stopped moving in the cylinder. The theta cell sample consisted of 23 theta cells collected from 12 rats.

For comparison purposes, a set of 25 place cells was selected from a previous study (Muller et al., 1987). Each of these cells had at least one clear firing field in a standard session. Most of these place cells were also recorded in a second standard session.

\section{Data analysis}

The location and spike strings were sorted into two 2-dimensional arrays, each of which was laid out so its elements corresponded to pixels. The first array counted the number of samples during which the rat was detected in each pixel (the time array). The second array counted the number of spikes that were fired while the rat was in each pixel (the spike array). By dividing each element of the spike array by the corresponding element of the time array, a firing rate array was formed. The time and rate arrays are of greatest interest. A color-coding scheme was used to visualize rate arrays. White encoded pixels that were never visited. Yellow was used to represent pixels visited in which the cell never fired. The color sequence orange, red, green, blue, purple was used to depict increasing firing rates. The number of pixels in each color category was scaled against the number of pixels in the next lower category, so that the ratio is 0.8 . We also made color-coded maps of the time array (dwell-time maps). These were coded with the same color sequence as the rate maps (yellow $<$ orange $<$ red $<$ green $<$ blue $<$ purple), but yellow was not treated specially and the ratio of the number of pixels in each color category was set to 1.0 instead of 0.8 .

\section{Correlation measures}

Three correlation techniques were used for analysis. Whenever inferential comparisons were made, $r$-to- $z$ transforms were made to normalize the data before performing $t$ tests (MacNemar, 1969). Since slightly over 500 pixels were visited in recording sessions, there were about 500 degrees of freedom for the "spatial correlations" and "spatial coherence" measures (see below). Using a 2-tailed $t$ test with $d f=500$, values of either measure more extreme than \pm 0.09 were significantly different from zero at the 0.05 confidence level, and values that were more extreme than \pm 0.12 exceed the 0.01 confidence level (MacNemar, 1969).

Spatial correlations were made between pairs of firing rate arrays on an element-by-element basis. When this was done for pairs of rate arrays from different sessions, the correlation indicated the repeatability of the spatial firing-rate distribution. When a correlation was made between 

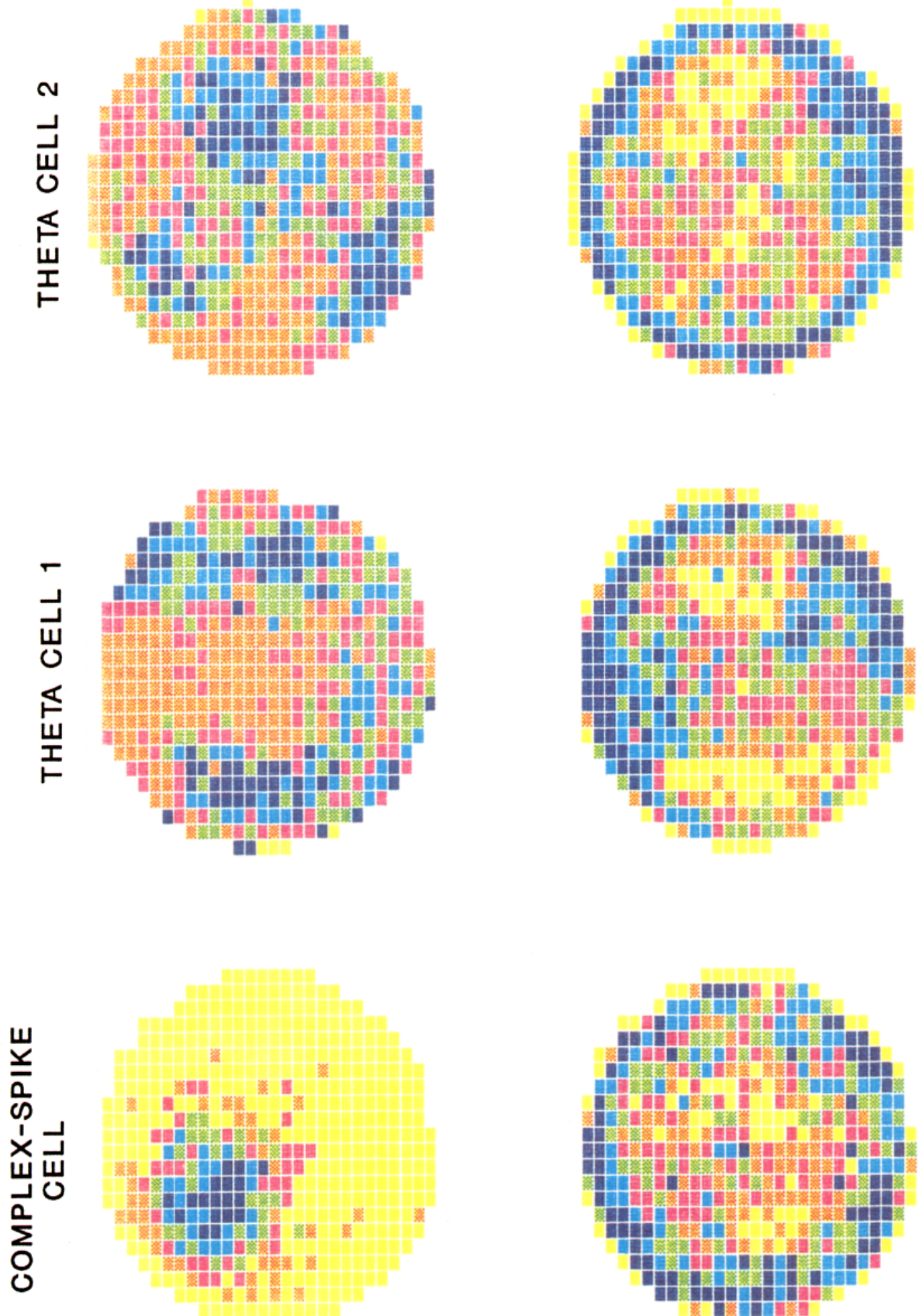

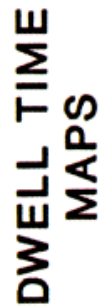

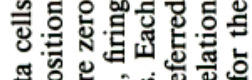

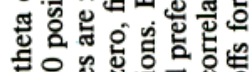

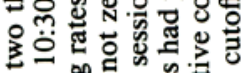

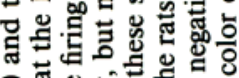

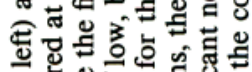

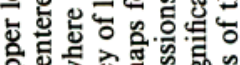

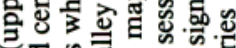

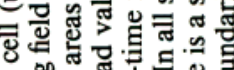

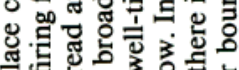

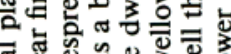
然逑. 死 空

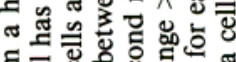

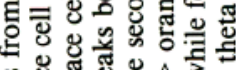

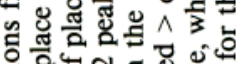
염녕면

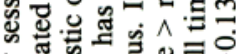

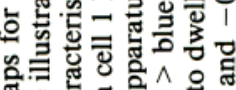

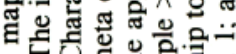

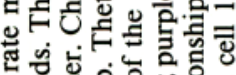

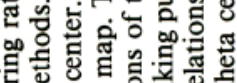
它记

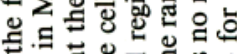
웡 过.

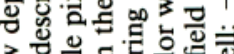

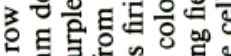

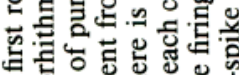
o 品 的. 政

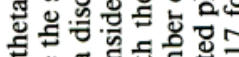

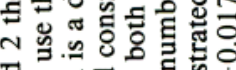

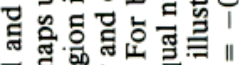

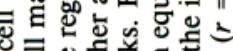
究记

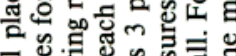

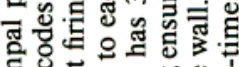

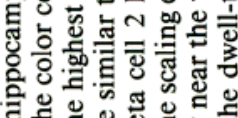

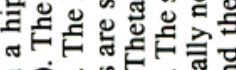
हิ宀

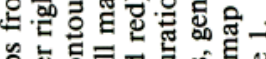
领

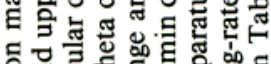

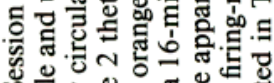
ผั

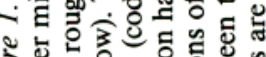

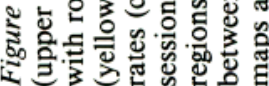


a rate array and a time array for a single session, the value indicated the dependency of firing on dwell time. In all such correlations, pixel locations that were unvisited were not included in the calculation.

Spatial coherence was used to measure the strength of spatial firing. It was computed for individual sessions by pairing the firing rate in each element of the rate array with the aggregate rate in the 8 nearest pixels. The rate for the neighbors was the sum of all spikes divided by the sum of dwell times. The single correlation value obtained from the rate array is a measure of the local smoothness of firing rate contours. Coherence is an autocorrelation computed at the distance between adjacent pixels. Positive coherence values indicate the presence of a spatial determinant of firing whose spatial frequency is lower than the distance between adjacent pixels.

Finally, angular cross-correlation measured the angular distribution of firing across pairs of sessions. This measure was used to determine how the angular distribution changed after rotations of the cue card. The method is described in detail in Muller and Kubie (1987). In brief, spikes and dwell time are sorted into $6^{\circ}$ angular bins for each session, and an angular firing rate distribution is constructed. For 2 sessions done on a single cell, the angular distributions can be compared by correlation. If one distribution is shifted with respect to the other in $6^{\circ}$ steps, the correlation coefficient is generated as a function of rotation. The angular rotation that produces the highest correlation is an estimate of the amount of firing pattern rotation. The magnitude of the highest correlation estimates the similarity of the 2 angular distributions.

\section{Analysis of locomotor state}

In addition to analyses based on the outcomes of entire sessions, 2 methods wcrc uscd to assess the extent to which theta cell firing patterns arose from variations in locomotor state.

Selecting trajectories through particular regions of the apparatus was the first method used. This analysis was performed from videotape records of the recording sessions where action potential activity was recorded on the audio channels. Using the color-coded firing-rate map obtained from a session, 2 regions were selected: one a high-rate region and one a low-rate region. These regions were outlined on the video monitor. When, in viewing the videotape record, the rat was seen to move through either region, the firing rate of the cell was measured over a 5-sec interval. Two types of samples were recorded: (1) when the rat moved steadily for $5 \mathrm{sec}$ and passed through the region, and (2) when the rat was still for $5 \mathrm{sec}$ within the region.

Sorting data into speed categories was the second method of detecting the modulation of theta cell firing by locomotor state. This was done by sorting the data from a recording session according to whether the rat's average speed was above or below $6.9 \mathrm{~cm} / \mathrm{sec}$ during each $0.5-\mathrm{sec}$ interval. The rat's location every $0.5 \mathrm{sec}$ was sampled; the distance traveled since the last sample was computed and converted to speed. The short integration interval was chosen so that each path segment was likely to be linear or nearly linear. The average speed was chosen so that the rat had to move horizontally or vertically more than one pixel $(3.4 \mathrm{~cm})$ for the interval to fall into the higher category. With shorter distances, merely crossing a pixel boundary between data samples (as could occur with a head movement) could cause an interval to be counted as high speed. The data from 2 standard 16-min sessions were scanned for high-speed intervals. At most, 16 min of high-speed intervals were selected; in only one case were there too few intervals to yield 16 min of data. The combincd high-specd data set for a cell was then used to generate a high-speed firing-rate array. The spatial firing distribution in this array was then compared to the spatial distributions of the 2 unfiltered standard sessions.

\section{Results}

Description of the spatial firing of theta cells and comparison with complex-spike cells

The rate maps from theta cells were remarkably similar to each other in overall appearance and are distinctive from place-cell maps. Illustrative maps from a place cell and 2 theta cells are given in Figure 1 (see also Table 1). Whereas the place cell spatial distribution is best described as a localized firing field occupying well under half the cylinder area, the rate maps for the theta cells are better described as complex surfaces witn several regions of fast and slow firing. One of the striking differences in the maps is the presence of large zero-rate (yellow) regions for place cells and the virtual absence of such regions for theta cells. By inspection, it appears that the spatial signal for place cells is much more pronounced.

Many aspects of the spatial firing patterns can be used to charactcrize the theta class. We focused on the fraction of the apparatus area in which firing occurs, the extent of the contrast between fast and slow firing regions, the degree to which the firing pattern is reproduced in a second session for the same cell, and the smoothness of firing-rate contours. Each of these measures helps specify the spatial firing of theta cells and provides a means for comparing theta cells with place cells.

As seen from the maps of Figure 1, theta cells fired almost everywhere in the apparatus. On average, $97.9 \%$ of the sampled pixels had firing rates greater than zero (range 94.3-99.2\%). Moreover, the existence of these few zero-rate pixels appears to be due to undersampling, since firing occurred in all pixels when pixels with dwell times less than 1 sec were ignored. The average firing area for place cells was consistently lower; for place cells the mean fraction of pixels with greater than zero rates was $36.6 \%$ (range $13-60 \%$ ). Ignoring pixels with dwell times $<1 \mathrm{sec}$ increased the mean firing area to only $46.1 \%$. The ubiquity of theta cell firing arose from the tendency of theta cells to fire at about 10 spikes/sec when the rat is stationary and to increase whenever the rat moves (Ranck, 1973). By contrast, place cells can be silent for many seconds at a time, independent of behavior, when the rat is outside the cell's firing field.

Although theta cells fired throughout the apparatus, the rates in all regions were not equal. The magnitude of spatial variations in firing was estimated by finding firing rates in the regions of fastest and slowest firing. To do this, the firing rate within an almost square window 3 pixels wide and 4 pixels high $(10.2 \times$ $11.2 \mathrm{~cm}$ ) was found in all regions of the cylinder, and the highest and lowest rates were determined. For theta cells, the mean in the region with the highest rate was $32.6 \mathrm{AP} / \mathrm{sec}( \pm 14.3 \mathrm{AP} /$ sec $\mathrm{SD}$ ), and the mean in the region with the lowest rate was 13.8 AP/sec ( $\pm 7.9 \mathrm{AP} / \mathrm{sec} \mathrm{SD})$. The mean ratio for high-rate to low-rate regions ("firing contrast") was 2.51 ( $\pm 0.55 \mathrm{SD})$. This is in contrast to the extreme situation for place cells, where the firing in the low-rate region was exactly zero for all cells.

For spatial variations in theta cell firing to be interpreted as directly or indirectly due to position, it is necessary to demonstrate that the spatial pattern is repeatable from session to session. If the pattern were due to "noise" (i.e., temporal variations independent of position), the intersession correlation should approach zero. Repeatability was measured by calculating pixel-by-pixel correlations between the firing rate distributions of pairs of sessions for 18 theta cells. In all cases the repeatability was positive and in all but one case was statistically greater than zero. The mean repeatability was 0.270 , which, for this group, is statistically greater than zero $(t=9.44, d f=17$, $p \ll 0.001)$. We argue that a null hypothesis of zero for repeatability is correct from the finding that pixel-by-pixel correlations between firing-rate distributions of sessions from different cells were indistinguishable from zero (mean $=0.008 ; t$ $=0.04 ; d f=22 ; p>0.1$ ). The mean repeatability for place cells was 0.678 , significantly higher than for theta cells $(t=6.75, d f$ $=32, p \ll 0.001)$. Both classes of cells, therefore, satisfied stationarity, but repeatability for place cells was more pronounced than for theta cells.

Spatial coherence provided a different way of vicwing spatial firing patterns. As a correlation measure, spatial coherence was 
Rate $X$ Time
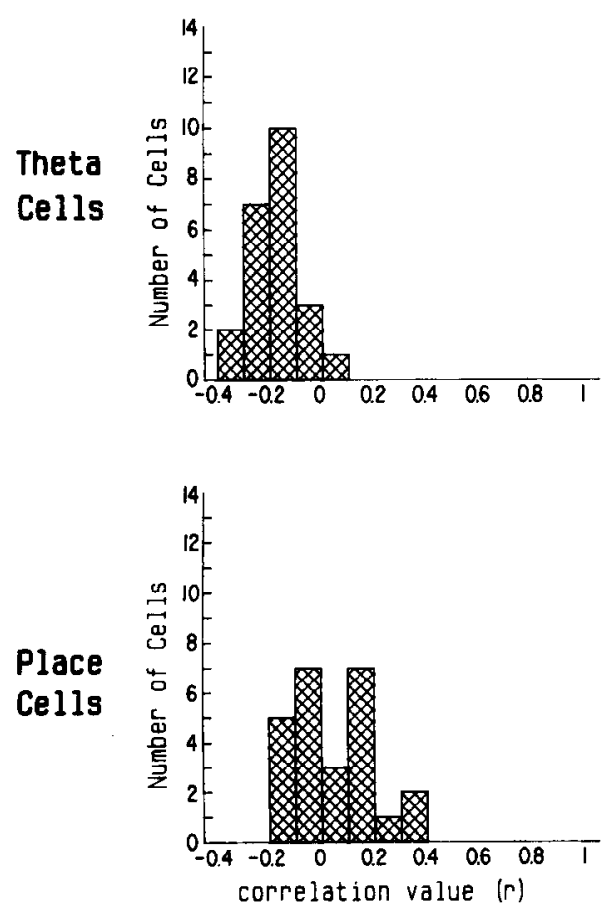

Coherence
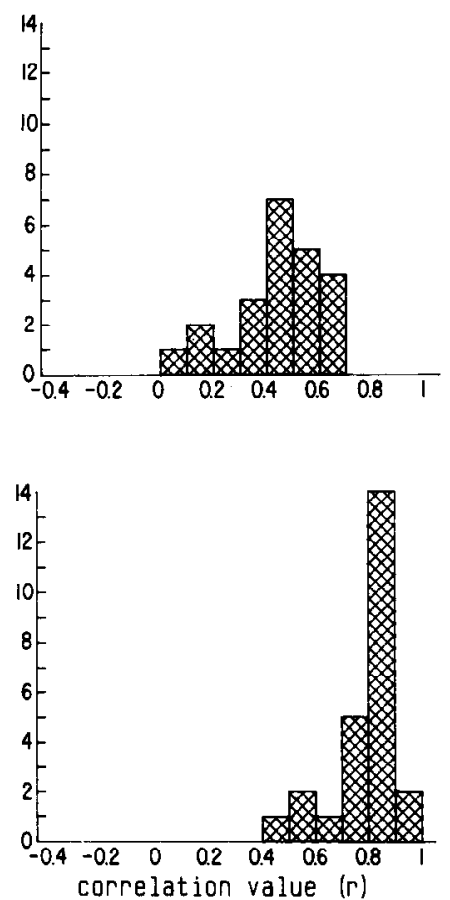

Rate $X$ Rate (2 sessions)
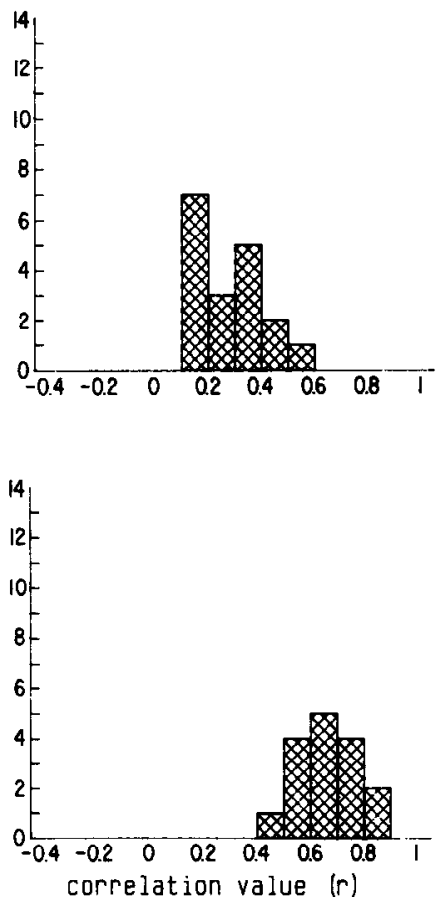

Figure 2. Distribution of rate-by-time, coherence and rate-by-rate correlations for the populations of theta cells and place cells. (For theta cells: $n=25$ for coherence and rate-by-time, $n=18$ for replications. For place cells: $n=23$ for coherence and rate-by-time, $n=16$ for replications.)

expected to be high when the firing rate in a pixel is similar to the firing rate in neighboring pixels, and, therefore, will measure the local smoothness of a firing-rate distribution. The mean coherence for the theta cell sample was 0.466 (range $0.03-0.66$ ). This value was much higher than the mean coherence scores after the spatial distribution of firing rates for each cell was shuffled $[t=10.85$ on a paired $t$ test, $d f=22, p \ll 0.001$; the mean coherence for the randomized set $(-0.018)$ was not significantly different from zero; the range of randomized values was -0.12 to 0.07$]$. Nevertheless, the coherence for place cells was greater than for theta cells. The mean for place cells was 0.805 (range $0.47-0.90$ ), and the values of only 3 place cells fell into the range for theta cells. Not surprisingly, the hypothesis that these 2 groups have identical mean coherence is rejected ( $t$ $=6.75, d f=32, p \ll 0.001$ ). It therefore appears that the firing contours of theta cell sessions were much smoother than chance, but not as smooth as for place cells. As depicted in Figure 2, the coherence scores for both groups appear to parallel the repeatability scores, but are a little higher.

\section{Environmental control over the spatial firing of theta cells}

If the origins of the spatial firing of theta cells are similar to those of place cells, they ought to respond in a similar manner to environmental manipulations. For place cells, rotations of the white cue card caused equal rotations of firing fields, regardless of the location of the fields (Muller and Kubie, 1987). Cue-card rotations were performed on 8 theta cells. By visual inspection and angular cross-correlation analysis, the firing patterns of 7 of the theta cells rotated with the cue card. For these cells, the angular cross-correlation reached a peak value within $\pm 18^{\circ}$ of the actual rotation of the cue; the maximal correlation values ranged from 0.39 to 0.70 . For the eighth cell the spatial firing was radially symmetrical (the firing dropped off equally in all directions from the cylinder center), so the effects of card rotation could not be detected. The effects of a $90^{\circ}$ counterclockwise card rotation on the firing of a pair of simultaneously recorded cells are apparent from the rate maps in Figure 5. The $90^{\circ}$ counterclockwise card rotation yielded a $90^{\circ}$ firing pattern rotation for the first cell (comparison of first and third sessions; $r=0.44)$. For the second cell the firing pattern rotated $102^{\circ}(r$ $=0.55)$. Thus, the spatial firing patterns of theta cells rotate with the cue card. The same response is seen for place cells. The hypothesis of a strong connection between the spatial firing properties of theta cells and place cells passes a simple test, but requires additional tests of the effects of other environmental manipulations.

\section{The contribution of locomotion and other behavioral variables to theta cell firing}

Earlier work showed that the firing of theta cells is known to be related to the ongoing behavior of the rat. In particular, theta cell firing is faster when a rat walks or runs than when it is still (Ranck, 1973; Sinclair et al., 1982). The dependence of theta cell firing on locomotor state was demonstrated by sorting sequential 0.5 -sec intervals into 2 categories depending on whether the animal's running speed was less than or greater than a selected threshold. For reasons stated in the methods, the speed threshold selected was $6.9 \mathrm{~cm} / \mathrm{sec}$. For each of 16 cells, 2 standard sessions were used to create a composite session in which the rat's speed was greater than the threshold and a second composite when the rat's speed was less than threshold. Firing rates during high-velocity composites were consistently higher than in low-velocity composites. The mean ratio was 1.65 [range $2.30-1.22 ; t$ (ratio $=1.0)=8.1 ; d f=15 ; p<0.001]$. Thus, our 
work agrees with previous studies that reported increased theta cell firing with locomotion.

An interesting relationship between behavior and spatial firing was found by calculating the correlation between the amount of time a rat spent in a pixel with a cell's firing rate in the same pixel. For all but onc ccll there was a negative correlation between the dwell time in a pixel and the firing rate in that pixel. The mean correlation of -0.163 was significantly less than zero $(t=8.22 ; d f=22 ; p<0.001)$. The tendency for regions of high dwell times to have low firing rates is visible in the rate and time maps of Figure 1 for both theta cells. When the same analysis was done for place cells, the mean rate/dwell-time correlation of 0.027 was indistinguishable from zero $(t=-0.84$; $d f=22 ; p>0.05)$. This demonstrates that the observed spatial firing patterns are not entirely location specific. In other words, some component of the observed spatial firing is due to behavior.

\section{Locomotion-independent analysis of spatial firing}

Although the relationship between dwell time and firing rate is not very strong, it is still possible that spatial rate variations arise entirely from the locomotor correlate. The analyses below each show that there is a major component of spatial firing that is independent of locomotion.

If only the spatial distribution of resting and locomotion is responsible for spatial firing variations, such variations should be reduced or eliminated by restricting analysis to either the walking state or the resting state. A videotape analysis of the contribution of locomotion was made by first selecting highand low-rate regions of the apparatus and then measuring firing during individual trajectories of the rat into these regions. Entries were sorted into those in which the rat passed through the region and those with long bouts of immobility in the region. Videotape analysis was performed on the 4 theta cells with useful videotape records.

We found at most 3 episodes of immobility in either selected region for any of the cells. With this limited sample, the differences in firing rate between the fast and slow regions cannot be considered reliable. Nevertheless, as expected, firing during immobility in each region was invariably slower than during locomotion in either region. In contrast, the firing rate during locomotion was higher in the high-rate region for each of the 4 cells, averaged over at least 10 episodes of walking through each region for each cell. Figure 3 (see also Table 2) shows the firing of a theta cell as the animal walked through the high- and lowrate regions; faster firing in the high-rate region is apparent. Table 3 shows that this response is typical: Theta cell activity was significantly higher in the high-rate region for each cell. The mean ratio of the rate in the high to the low regions was about 2.0. We take these observations to mean that locomotor state alone cannot account for the spatial firing patterns exhibited by theta cells. The size of the rate differences during locomotion and the infrequent occurrence of immobility together suggcst that the uneven spatial firing distributions are the result of a spatial firing correlate that is independent of locomotor state.

A more formal and comprehensive method of assessing spatial firing patterns with locomotor state was done with the method of locomotor-speed sorting. By selecting 0.5-sec intervals according to whether the rat moved a distance less than one pixel horizontally or vertically $(3.4 \mathrm{~cm})$, a low-speed map was constructed. On the other hand, if the rat's movement was great-
Table 2. Color codes for Figure $3 \mathrm{~A}$

$\underline{\text { Median rate in each color category (spikes/sec): }}$

\begin{tabular}{llllll}
\hline Orange & Red & Green & Blue & Purple & $\begin{array}{l}\text { Mean } \\
\text { session } \\
\text { rate }\end{array}$ \\
\hline 22.7 & 32.9 & 40.0 & 45.7 & 55.9 & 38.3 \\
\hline
\end{tabular}

er than $3.4 \mathrm{~cm}$, the intervals were used to create a high-speed map.

Sorting according to speed was carried out on the 16 theta cells for which at least 2 standard sessions were run. For 15 of the 16 cells, the coherence for the "session" created from combined high-speed intcrvals was greater than the mean of the 2 entire sessions from which the data were selected. This outcome is statistically improbable according to the binomial distribution $(p<0.001)$. In other words, the local smoothness of the spatial firing pattern was enhanced when variations in locomotor state were reduced. This result is contrary to the idea that the spatial firing distributions of theta cells are no more than reflections of the rat's tendency to walk through certain regions and to remain still in others. In addition, the magnitude of firing-rate variations was as great in high-speed composites as in original sessions. The mean firing-rate contrast for high-speed composites was 2.42 , compared to 2.51 for original sessions. A paired $t$ test did not reject the hypothesis that the contrasts were sampled from the same population $(t=1.63 ; d f=15 ; p>0.05)$. Thus, the increased smoothness of the spatial firing distributions did not come at the expense of global reductions in spatial firing-rate variations.

\section{Comparison of spatial firing patterns from simultaneously recorded theta cells}

Two important consequences arise if it is hypothesized that the global locomotor state is the fundamental determinant of theta

\begin{tabular}{lccl}
\hline $\begin{array}{l}\text { Table 3. Firing rates during walking trajectories in fast- and } \\
\text { slow-rate regions }\end{array}$ & $\begin{array}{l}\text { Low-rate } \\
\text { High-rate } \\
\text { region }\end{array}$ & $\begin{array}{l}\text { High/low } \\
\text { ratio }\end{array}$ \\
\hline Cell 1 & & & \\
Mean & 18.5 & 7.1 & 2.60 \\
SD & 3.5 & 3.3 & \\
$n$ & 20 & 20 & \\
Cell 2 & & & \\
Mean & 16.7 & 10.6 & 1.57 \\
SD & 2.9 & 3.2 & \\
$n$ & 18 & 19 & \\
Cell 3 & & & \\
Mean & 34.3 & 20.7 & \\
SD & 8.2 & 7.6 & \\
$n$ & 20 & 20 & \\
Cell 4 & & 34.5 & \\
Mean & 73.1 & 11.8 & \\
SD & 12.9 & 10 & \\
$n$ & 10 &
\end{tabular}

${ }^{a}$ Each rate is spikes/sec.

"Each of the high-rate means is statistically different from the low-rate mean for the same cell at the 0.01 confidence level. 


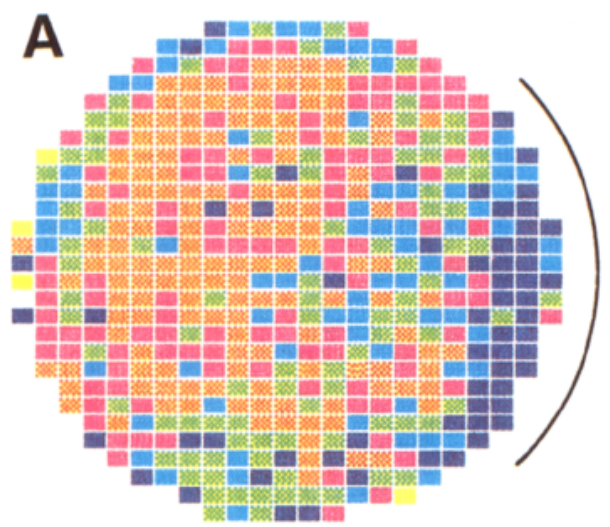

High-rate Region

Locomotion
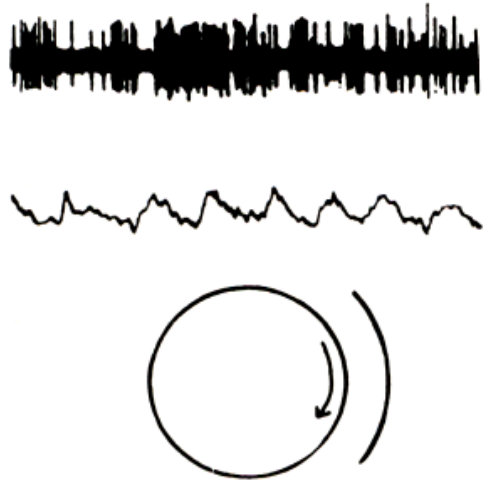

High-rate Region

Immobile
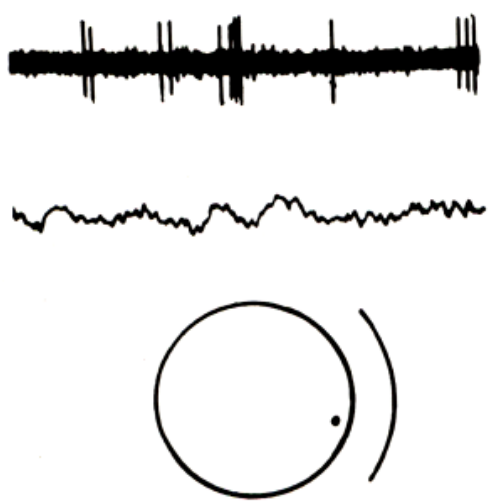

B
Low-rate Region

\section{Locomotion}

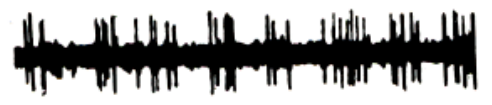

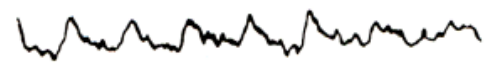

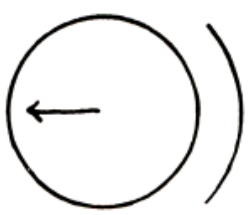

Low-rate Region
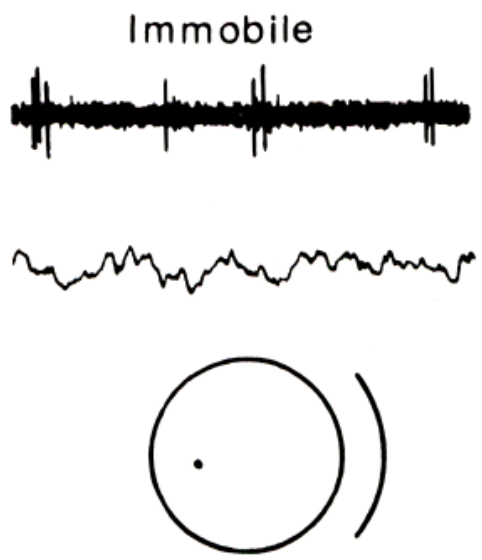

Figure 3. Behavioral independence of theta cell spatial firing. $A$, Firing rate map for a 16-min session recorded from a theta cell. (The lower firing-rate boundaries in spikes/sec for each color are: orange: $>0.0$; red: 28.3 ; green: 36.8 ; blue: 42.8 ; purple: 49.8 .) The location of the cue card is depicted with a black arc adjacent to the map. The high-firing region selected was a crescent-shaped strip adjacent to the cue card. The lowfiring region selected appears as a broad plane of mostly orange pixels away from the wall in the 9 o'clock location. $B$, Results of 4 behavioral samples in these 2 regions. One-second spike and EEG traces are depicted for each sample. In the upper left and upper right are examples of locomotor trajectories taken through the high-rate region and the lowrate region, respectively. The EEG shows theta rhythm in both. There were 41 spikes in the trajectory through the "high-rate" region and 21 in the trajectory through the "low-rate" region. These are representative traces taken from 10 samples through each of these 2 regions. When the rat was stationary, theta rhythm dissappeared and firing was lower in both regions. This is illustrated in the lower 2 quadrants where motionless samples are illustrated when the rate was in the high-rate region and the low-rate region. The illustrated infield rate is 12 spikes/sec and the outof-field rate is 8 spikes/sec.

cell firing. First, the temporal firing patterns of all theta cells in a given animal are expected to strongly resemble each other. Second, because the animal is in only one place at a time, the spatial firing patterns of all theta cells should also be very similar.
Recordings from pairs of theta cells did not support these predictions.

Five pairs of theta cells were simultaneously recorded for at least 2 sessions. The rate maps for experiments with 2 cell pairs 
Table 4. Color codes for Figure 4

Median rate in each color category (spikes/sec):

\begin{tabular}{lcccccc}
\hline & & & & & & \multicolumn{2}{c}{$\begin{array}{l}\text { Mean } \\
\text { session } \\
\text { rate }\end{array}$} \\
\hline Unit 1 session 1 & Orange & Red & Green & Blue & Purple & 25.9 \\
Unit 1 session 2 & 19.6 & 25.3 & 29.3 & 33.2 & 40.9 & 16.9 \\
Unit 1 session 3 & 12.6 & 16.5 & 18.6 & 21.7 & 25.7 & 18.3 \\
Unit 1 session 4 & 13.2 & 17.5 & 20.7 & 24.0 & 28.8 & 13.5 \\
Unit 2 session 1 & 27.8 & 13.7 & 16.8 & 19.5 & 24.3 & 35.7 \\
Unit 2 session 2 & 34.8 & 44.2 & 40.8 & 46.5 & 54.5 & 45.1 \\
Unit 2 session 3 & 32.7 & 42.8 & 51.4 & 58.0 & 66.9 & 38.2 \\
Unit 2 session 4 & 31.1 & 42.4 & 49.0 & 55.4 & 65.5 & \\
Dwell-time map lower boundaries for each color (secs): & & & & \\
Session 1 & 0.59 & 0.988 & 1.38 & 2.03 & 3.11 & \\
Session 2 & 0.71 & 1.08 & 1.54 & 2.08 & 3.09 & \\
Session 3 & 0.66 & 1.03 & 1.54 & 2.19 & 3.08 & \\
Session 4 & 0.41 & 0.74 & 1.11 & 1.71 & 3.33 & \\
\hline
\end{tabular}

are depicted in Figures 4 and 5 (see also Tables 4 and 5). By inspection of the illustrated examples (and the other cell pairs), the members of each pair of cells had different regions of highand low-rate firing. For instance, in the cell pair of Figure 4 there was a region of fast firing for cell 1 at $3-4$ o'clock for all sessions that corresponded to a region of slow firing for cell 2 . It therefore appears that individual theta cells had distinctive, cell-specific firing patterns even when both were modulated by exactly the same locomotor sequence. It follows that there is a detectable nonlocomotor determinant of the spatial firing pattern. In addition, cell-specific spatial firing cannot be accounted for by the spatial distribution of any other behavioral firing correlate that is common to the 2 cells.

The existence of cell-specific spatial firing was corroborated by numerical analysis. Three similarity calculations were made on the firing patterns of theta cell pairs in pairs of independent sessions. The mean similarity across sessions for each of the 10 cells was 0.27 , which is significantly greater than zero $(t=7.11$; $d f=9 ; p^{-} \ll 0.001$; Table 6 ). This was very close to the similarity calculated for the larger sample of replications reported above. In contrast, when similarity scores were calculated between the cells of a pair across sessions, the mean was close to zero (mean $=0.03 ; t=0.71 ; d f=4 ; p>0.1$ ). Cell specificity is demonstrated by the finding that the spatial firing pattern of a given theta cell predicted its own pattern in a second session, but not the pattern of another theta cell.

The third similarity calculation compared the spatial firing patterns of theta cell pairs during the same recording session. The average correlation for the 5 cell pairs was 0.21 , which is significantly greater than zero $(t=4.98 ; d f=4 ; p<0.001)$. This again shows the existence of a detectable behavioral modulation of theta cell firing which makes a common contribution to both spatial firing-rate patterns.

\section{Discussion}

\section{Firing correlates of theta cells}

A primary finding of the work reported here is that the firing of theta cells is spatially inhomogeneous. The spatial modulation of theta cell firing is weaker than that of hippocampal place cells but it can be seen if the rat's position is automatically tracked, as first reported by McNaughton et al. (1983). Theta cells exhibit above-zero firing rates in all regions of the cylindrical apparatus. For the typical cell, several rather large regions within the apparatus are associated with relatively low and high firing rates, where the firing rate in high-rate regions is about 2.5 times greater than in low-rate regions.

It is important to point out that the magnitude of the spatial rate variations is greater than our estimate of the locomotiondependent variations of rate. This is a strong indication that spatial firing is not an incidental property of theta cells. Two other general features of theta cell activity deserve mention. First, the spatial firing patterns were stable across sessions separated by several days. Second, as shown with spatial coherence, theta cell spatial firing is smoother than chance although it is

Figure 4. Spatial firing of 2 simultaneously recorded theta cells for 4 sessions. The upper 2 rows illustrate the spatial firing distributions of 2 theta cells recorded simultaneously for 4 successive sessions. Spatial firing patterns for the 2 cells are clearly distinguishable. For instance, there is a region of high firing in cell 1 in the 3-4 o'clock region which corresponds to a region of low firing for cell 2 . Correlations between the rate arrays are low and bear this out. (For the 4 sessions: $+0.162,+0.134,+0.163$, and +0.271 . All are significant at the 0.05 level.) On the other hand, the spatial firing patterns for each cell are repeatable for all 4 sessions. For instance, the regions of high firing and low firing described above repeat in each session. The rate-array correlations for each replication with the first session are all moderately high and significant (Unit 1, S2: +0.444, S3: +0.237 , and S4: +0.264 ; Unit 2, S2: $+0.452, \mathrm{~S} 3:+0.311$, and S4: +0.357$)$. The bottom row illustrates the dwell-time maps for these 4 sessions. Each of these has a low but significant $(p<0.05)$ negative correlation with each of the corresponding firing rate arrays for both theta cells. (Unit $1: r=-0.128,-0.105,-0.141$, and -0.232 ; Unit $2: r=-0.197,-0.202,-0.303$, and -0.410 .) The lower boundaries of the color cutoffs for the maps are listed in Table 4. 

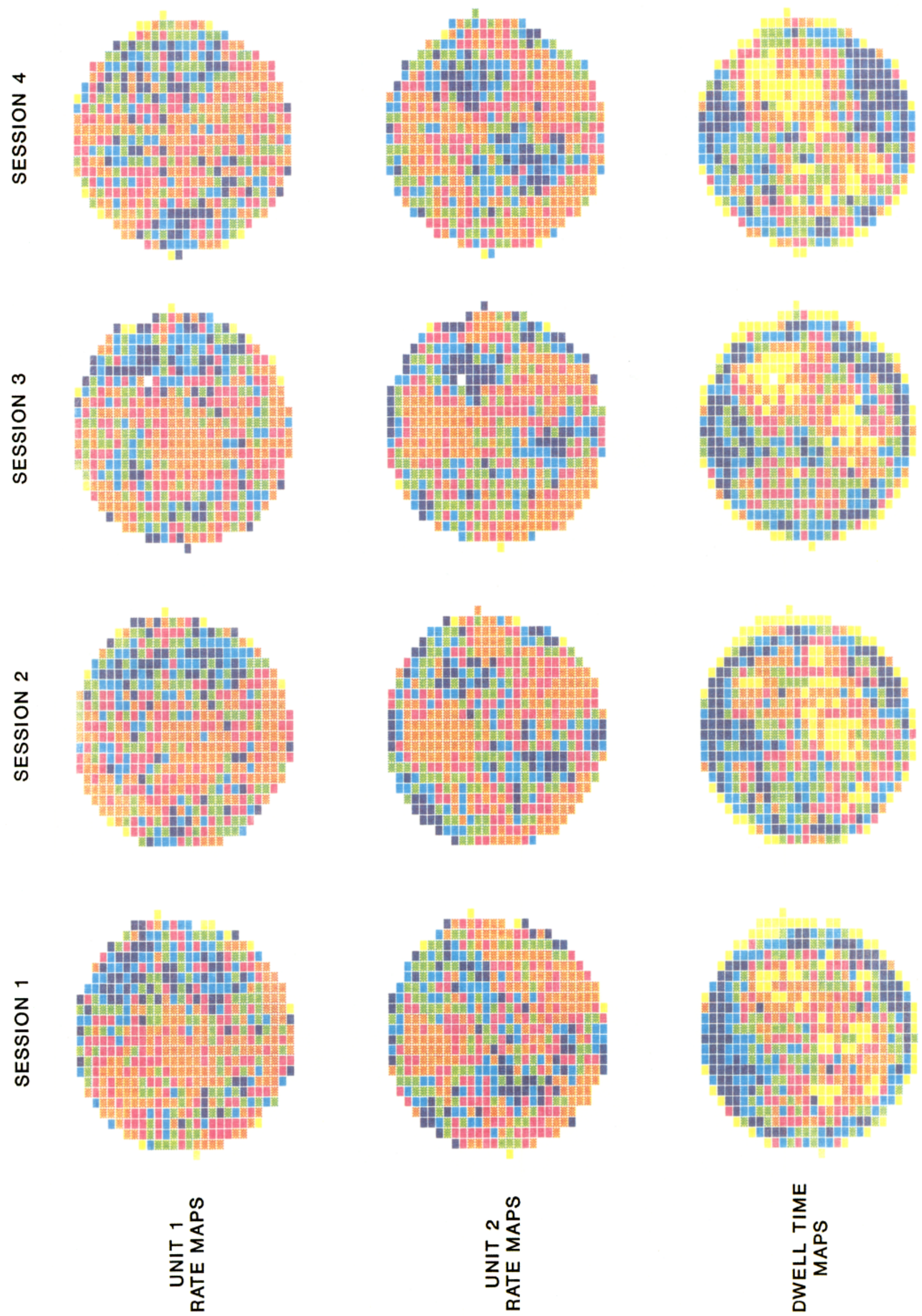

号点

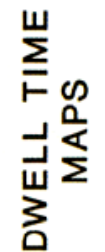




\begin{tabular}{|c|c|c|c|c|c|c|}
\hline \multicolumn{7}{|c|}{ Median rate in each color category (spikes/sec): } \\
\hline & Orange & Red & Green & Blue & Purple & $\begin{array}{l}\text { Mean } \\
\text { session } \\
\text { rate } \\
\end{array}$ \\
\hline Unit 1 session 1 & 26.7 & 33.7 & 39.5 & 44.3 & 51.4 & 34.8 \\
\hline Unit 1 session 2 & 26.3 & 32.3 & 36.6 & 41.3 & 48.8 & 33.1 \\
\hline Unit 1 session 3 & 16.3 & 20.5 & 23.4 & 26.8 & 32.6 & 21.4 \\
\hline Unit 2 session 1 & 10.3 & 14.6 & 17.1 & 19.0 & 24.0 & 15.4 \\
\hline Unit 2 session 2 & 10.0 & 15.0 & 17.7 & 20.4 & 24.5 & 15.4 \\
\hline Unit 2 session 3 & 8.5 & 12.5 & 15.4 & 18.1 & 22.5 & 13.2 \\
\hline \multicolumn{7}{|c|}{ Dwell-time map lower boundaries for each color $(\mathrm{sec})$ : } \\
\hline Session 1 & 0.81 & 1.13 & 1.46 & 2.04 & 2.82 & \\
\hline Session 2 & 0.84 & 1.23 & 1.63 & 2.03 & 2.78 & \\
\hline Session 3 & 0.86 & 1.26 & 1.56 & 2.03 & 2.64 & \\
\hline
\end{tabular}

considerably more jagged than that of place cells. Reproducibility and smoothness are further indications that spatial firing is a fundamental property of theta cells.

A good deal of the Results section was concerned with the origins of the spatial modulation of theta cell firing. In particular, we focused on the possibility that the positional variations in theta cell rates were secondary to the animal's propensity to remain stationary in certain places and to walk or run through other places. This attention to the animal's locomotor state was appropriate for 2 main reasons. First, previous work showed that theta cell firing covaries with locomotion such that running is associated with higher firing rates than immobility (Ranck, 1973; O'Keefe, 1976; Sinclair et al., 1982). Second, because of the pellet-chasing task used in the present experiments, the locomotor state was the predominant source of variation in the animal's behavior. We argue that there was a measurable locomotor component of theta cell firing, but that locomotion by itself was not sufficient to account for the spatial firing patterns of theta cells. This attention to locomotion does not imply that a more detailed analysis of theta cell firing correlations with behavior would be fruitless.

The modulation of theta cell firing by locomotion was disccrnible in 2 ways. First, retrospective viewing of videotapes directly revealed the tendency of theta cells to be relatively quiet during immobility and to be relatively active during locomotion, independent of whether the animal was in a high- or a lowfring-rate region. Second, firing rates in "high-speed" composite sessions were reliably higher than firing rates during "low-speed" composites for the same cell. There is no doubt that during our recording sessions locomotion was a major determinant of theta cell firing.
Similar analyses led to the conclusion, however, that the locomotor state could not fully account for theta cell firing. First, the viewing of videotapes revealed clear differences in the firing rate of a single cell when the animal ran through a low-rate region compared to a high-rate region; thus, regional differences remained even when behavior was held constant. Second, when analysis was restricted to only walking or running, as was done with the "high-speed" sessions, the orderliness of spatial firing patterns increased with no decrease in the magnitude of spatial firing variations. Third, when pairs of simultaneously recorded theta cell pairs were recorded for 2 or more sessions, the average pixel-by-pixel correlation was zero when the firing for one cell in the first session was compared to the firing of the other cell in the second session. By contrast, the spatial firing pattern of each member of the pair showed a reliable positive correlation from session to session. We conclude that there was a behaviorindependent component of the spatial firing pattern of individual theta cells. The firing of theta cells thus appears to be an amalgam of the location- and motion-specific components.

The results presented here disagree with one of the conclusions about theta cell firing drawn by Christian and Deadwyler (1986). Christian and Deadwyler (1986) found a double dissociation between the firing correlates of theta cells and complex-spike (place) cells. They reported location-specific firing for complexspike cells, but saw no change in the firing of these cells during a conditioning procedure. By contrast, they found that theta cell firing changes during conditioning, but that such cells did not show inhomogeneities in spatial firing. It is possible that the difference between our results and those of Christian and Deadwyler (1986) arises from differences in the behavioral conditions in the 2 studies. In our opinion, however, the results disagree

Figure 5. Spatial firing patterns for 2 simultaneously recorded theta cells with a replication and a cue rotation. The top 2 rows illustrate the firingrate distributions for the 2 cells across 3 sessions. Sessions 1 and 2 are replications. As in Figure 4, there is good replicability of each cell's firing patterns across the 2 sessions. (The spatial correlations between rate arrays of the second session and the first are +0.284 for unit 1 and +0.309 for unit 2.) Also, the rate maps for the 2 cells are clearly distinctive from each other. (This is indicated by the rate-array correlations between the 2 cells for the 3 sessions of $+0.154,+0.460$, and +0.230 .) The location of the cue card in each session is depicted with a black arc adjacent to the map. Session 3 was run with the cue card rotated $90^{\circ}$. For both cells the firing-rate distribution rotates with the cue card. The dwell-time maps for the 3 sessions are illustrated in the bottom row. There is a significant negative correlation between the time arrays and the rate arrays recorded in the same session for 5 of the 6 comparisons [Unit $1, \mathrm{~S} 1:+0.022$ (not significant), S2: -0.103 , and S3: $-0.128 ;$ Unit 2, S1: -0.154, S2: -0.191 and S3: -0.141 .] The lower boundaries of the color cutoffs for the maps are listed in Table 5 . 

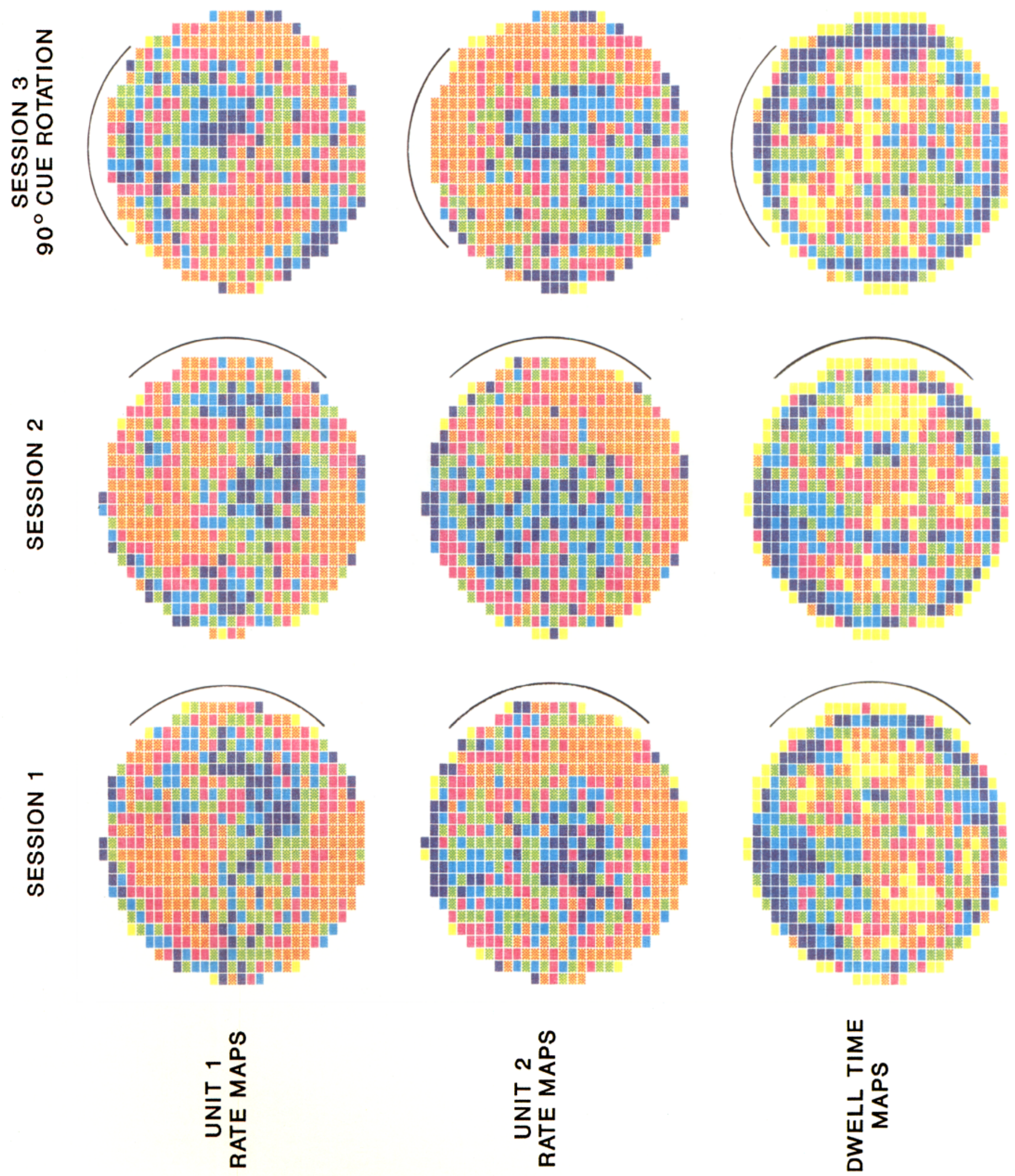
Table 6. Correlations between firing-rate arrays in two-cell sessions

\begin{tabular}{lcll} 
& $\begin{array}{l}\text { Single } \\
\text { cell: } \\
\text { across } \\
\text { sessions }\end{array}$ & $\begin{array}{l}\text { Across } \\
\text { cells: } \\
\text { within a } \\
\text { session }\end{array}$ & $\begin{array}{l}\text { Across } \\
\text { cells: } \\
\text { across } \\
\text { sessions }\end{array}$ \\
\hline Mean correlation & $+0.268^{b}$ & $+0.212^{b}$ & $+0.031^{\circ}$ \\
$\mathrm{SD}^{a}$ & 0.113 & 0.085 & 0.087 \\
$n$ & 10 & 5 & 5
\end{tabular}

"Standard deviations are in $z$-transformed correlation units.

"Significantly different from zero and from the across-cell/across-session mean at the 0.01 level.

Not significantly different from zero.

because the rat tracking system used by Christian and Deadwyler (1986) did not have enough spatial resolution to reveal the phenomenon reported here.

By contrast, our results are in agreement with those of McNaughton et al. (1983). These authors found an arm-specific component of theta cell firing on the radial-arm maze. They concluded that this could be due to "spatial" firing per se or, less likely, to an arm-specific behavioral effect. Our results, however, extend the results of McNaughton et al. in at least 3 ways. First, recording in a circular apparatus with a continuous floor revealed a rather simple structure of spatial firing. Second, the sharpened spatial firing patterns produced by considering only high-velocity composites greatly strengthen the argument that spatial firing is not completely secondary tc sucomotor variables. Finally, recording from 2 cells at a time demonstrated cell specificity in spatial firing.

It is important to note that we still cannot reject the idea that some unidentified behavior or behavioral state creates the observed spatial firing patterns. This reservation is inherent in the problem. To record the spatial firing of theta cells, the rat needs to be awake and freely moving. In an awake and freely moving animal, innumerablc behaviors or bchavioral states can be described, and it is impossible to account for all of them. The best one can do is examine the major candidate sources of variance and assess their contributions.

\section{The connectivity of theta cells}

As noted in the introduction, cells recorded from Ammon's horn in freely moving rats can be divided into theta cells and complex-spike cells on electrophysiological grounds (Ranck, 1973). Although both classes are defined on the basis of the firing characteristics, anatomical identifications can be made. There is little doubt that complex-spike cells are pyramidal cells. They are recorded almost exclusively near the pyramidal cell layer (Fox and Ranck, 1975) and have many of the physiological characteristics of pyramids (Fox and Ranck, 1981). Theta cells appear to be a broader class. Fox and Ranck (1975) found theta cells predominantly in stratum oriens of CA1, stratum radiatum of CA3, and throughout the hilus. These authors found that virtually every cell recorded outside of the pyramidal cell layer could be classified as a theta cell and concluded that theta cells include essentially all nonpyramidal neurons. It seems likely, for instance, that the basket cells described by Lorente de No (1934) are theta cells, but since theta cells are recorded in regions where basket cells are not found (e.g., in the most dorsal part of stratum oriens of CA1), the category must include other nonpyramidal cell types. Several studies found that cells that can be identified as nonpyramids on the basis of recording location or intracellular dye injection have the firing characteristics of inhibitory interneurons (Andersen et al., 1964a, b; Schwartkroin and Mathers, 1978; Miles and Wong, 1984; Lacaille et al., 1987). Fox and Ranck (1981) found that theta cells also behave in this manner. We therefore assume, as a working hypothesis, that theta cells are a heterogeneous class of inhibitory interneurons. Here we consider how the postulated anatomical relationships between theta cells and complex-spike cells might be reflected in the spatial firing properties of each type. We also consider the functional significance of (possibly indirect) excitatory inputs onto the interneurons from the medial septum.

The characteristic appearance of theta cell firing-rate maps has interesting implications with respect to the excitatory connections from complex-spike cells onto theta cells. We find that there are about 3 or 4 regions of high firing rate for theta cells. Moreover, the size of each high-rate region is about the size of the firing fields of place cells recorded under identical circumstances (Muller and Kubie, 1987; Muller et al., 1987). It is therefore possible that each high-rate region for a theta cell reflects the input from a single place cell, with the implication that each place cell can drive the theta cell. In other words, we suggest that the spatial firing characteristics of theta cells reflect the effective convergence of place cells onto theta cells, an idea first introduced by McNaughton et al. (1983). In addition, it is our argument that if the convergence were very high, it would be impossible to see islands of relatively intense firing in theta cell rate maps.

Our estimate for convergence of about 4 is small compared to the estimate of about 10-20 made on electrophysiological grounds by Miles (personal communication, 1988). Miles compared the maximal EPSP that could be evoked in interneurons by strong field stimulation to the size of the EPSP that followed discharge of a monosynaptically connected pyramidal cell. His estimate of the converge is based on the ratio of the sizes of the maximal and single-input EPSPs. ${ }^{\prime}$ Our estimate can be brought into closer agreement with the electrophysiological estimates by considering the existence of "silent" place cells (Kubie and Ranck, 1983; Muller and Kubie, 1987; Muller et al., 1987; Thompson and Best, 1989). A silent place cell is one that does not fire in the environment of immediate interest, but is known to have a firing field in some other environment. If such cells exist in large numbers, or if complex-spike cells with similarly located firing fields preferentially synapse on a theta cell, the effective convergence of about 4 can be reconciled with the electrophysiological estimates.

The inhibitory projections from theta cells to complex-spike cells may mediate the relationships between complex-spike cell firing and the state of the hippocampal EEG. We observed that spatial firing in place cells is more robust when the hippocampus is generating the theta EEG pattern than when the EEG is characterized by large irregular activity (Kubie et al., 1985). In particular, spatial firing specificity (the ratio of the mean in-field firing to the mean out-of-field firing) is greater during the theta state. The higher specificity may in part arise from the higher overall rate of (inhibitory) theta cell firing during theta (Ranck, 1973). If many theta cells converge on each place cell, it is unlikely that spatial variations of the total inhibition would

\footnotetext{
'A similar value can be obtained from the data in LaCaille et al. (1987), who reported an average of $2.16 \mathrm{mV}$ for the EPSP produced by stimulating pyramidal cells and showed much larger responses after stimulation in stratum radiatum (their figures 1 and 6 ).
} 
exist, since spatial variations of theta cell firing would be averaged out by summation. The suggested role of theta cells in cleaning up the spatial firing of place cells bears a superficial similarity to the mechanisms of inhibitory surround ( $\mathrm{Ha}$. line et al., 1961), but differs in that the firing rate of place cells in the center of their firing field actually increases during theta, since a decrease would be expected on the basis of lateral inhibition alone.

Cells of the medial septum are a second class of neurons that appear to have a strong influence on theta cells. Many neurons in the rat medial septum behave like theta cells in that they are highly rhythmic (Petsche et al., 1962) and increase their firing during hippocampal theta (i.e., whenever the rat walks or runs; Ranck, 1973). Medial septal neurons appear to be the source of theta cell rhythmicity in that cutting the connection between these 2 groups (by cooling the fornix) abolishes hippocampal rhythmicity but has no effect on the rhythmicity of cells in the medial septum (Stewart and Fox, 1989). It therefore appears that the medial septal inputs to the hippocampus are the source of the theta and locomotor correlates seen in hippocampal theta cells. On the other hand, it seems unlikely that this input contributes directly to spatial firing.

\section{General conclusions}

The firing properties of hippocampal theta cells appear to be more complex than when first described by Ranck in 1973. Our work demonstrates at least 2 dissociable correlates of theta cell activity, one concerned with the animal's position and the other with the animal's locomotor state. It seems likely that these correlates reflect the convergent influences of hippocampal place cells (which fire in association with location) and of medial septal cells (which pace and perhaps control the hippocampal theta rhythm). The finding of location-specific firing for theta cells bolsters the idea of O'Keefe and Nadel (1978) that the rat hippocampus is concerned with signaling the animal's position within an abstract representation of the environment. Muller and Kubie (1987) elaborated on O'Keefe and Nadel's hypothesis, suggesting that the hippocampus is involved in calculating optimal trajectories. Since information about movement and location is needed for efficient trajectory computation, the convergence of these 2 types of information on theta cells is in keeping with this idea.

\section{References}

Andersen, P., J. C. Eccles, and Y. Loyning (1964a) Location of postsynaptic inhibitory synapses on hippocampal pyramids. J. Neurophysiol. 27: 592-607.

Andersen, P., J. C. Eccles, and Y. Loyning (1964b) Pathway of postsynaptic inhibition in the hippocampus. J. Neurophysiol. 27:608619.

Best, P. J., and J. Ranck, Jr. (1982) Reliability of the relationship between hippocampal unit activity and sensory-behavioral events in the rat. Exp. Neurol. 75: 652-664.

Christian, E. P., and S. A. Deadwyler (1986) Behavioral functions of hippocampal cell types: Evidence of two non-overlapping populations in the rat. J. Neurophysiol. 55: 331-348.

Fox, S. E., and J. B. Ranck, Jr. (1975) Localization and anatomical identification of theta and complex-spike cells in the dorsal hippocampal formation of rats. Exp. Neurol. 49: 299-313.

Fox, S. E., and J. B. Ranck, Jr. (1981) Electrophysiological charac- teristics of hippocampal complex-spike and theta cells. Exp. Brain Res. 41: 399-410.

Hartline, H. K., F. Ratliff, and W. H. Miller (1961) Inhibitory interactions in the retina and its significance in vision. In Inhibition, E. Flory, ed., pp. 241-284, Pergamon, New York.

Knowles, W. D., and P. A. Schwartzkroin (1981) Local circuit synaptic interactions in hippocampal brain slices. J. Neurosci. 1: 318-322.

Kubie, J. L. (1984) A driveable bundle of microwires for collecting single-unit data from freely moving rats. Physiol. Behav. 32: 115118.

Kubie, J. L., and J. B. Ranck, Jr. (1983) Sensory-behavioral correlates of individual hippocampal neurons in three situations: Space and context. In Neurobiology of the Hippocampus, W. Seifert, ed., pp. 433-447, Academic, New York.

Kubie, J. L., R. U. Muller, and S. E. Fox (1985) Firing fields of place cells: Interim report. In Electrical Activity of the Archicortex, G. Buzasaki and C. H. Vanderwolf, eds., Hungarian Academy of Sciences, Budapest.

Lacaille, J.-C., A. L. Mueller, D. D. Kunkel, and P. A. Schwartzkroin (1987) Local circuit interactions between oriens/alveus interneurons and CA1 pyramdal cells in hippocampal slices: Electrophysiology and morphology. J. Neurosci. 7(7): 1979-1993.

Lorente de No, R. (1934) Studies on the structure of the cerebral cortex. II. Continuation of the study of the Ammonic system. J. Psychol. Neurol. 46: 113-177.

MacNemar, Q. (1969) Psychological Statistics, 4th ed., Wiley, New York.

McNaughton, B. L., C. A. Barnes, and J. O'Keefe (1983) The contributions of position, direction and velocity to single unit activity in the hippocampus of freely moving rats. Exp. Brain Res. 52: 41-49.

Miles, R., and R. K. S. Wong (1984) Unitary inhibitory synaptic potentials in the guinea-pig hippocampus. J. Physiol. 356: 97-1 13.

Muller, R. U., and J. L. Kubie (1987) The effects of changes in the environment on the spatial firing of hippocampal complex-spike cells. J. Ncurosci. 7(7): 1951-1968.

Muller, R. U., J. L. Kubie, and J. B. Ranck, Jr. (1987) Spatial firing patterns of hippocampal complex-spike cells in a fixed environment. J. Neurosci. 7(7): 1935-1950.

O'Keefe, J. (1976) Place units in the hippocampus of the freely moving rat. Exp. Neurol. 51: 78-109.

O'Keefe, J. (1979) A review of the hippocampal place cells. Prog. Neurobiol. 13: 419-439.

O'Keefe, J., and D. H. Conway (1978) Hippocampal place units in the freely moving rat: Why they fire where they fire. Exp. Brain Res. 31: $573-590$.

O'Keefe, J., and J. Dostrovsky (1971) The hippocampus as a spatial map. Preliminary evidence from unit activity in the freely-moving rat. Brain Res. 34: 171-175.

O'Keefe, J., and L. Nadel (1978) The IItppocampus as a Cognitive Map, Clarendon, Oxford.

Olton, D., M. Branch, and P. Best (1978) Spatial correlates of hippocampal unit activity. Exp. Neurol. 58: 387-409.

Petsche, H., C. Stumpf, and G. Gogolak (1962) The significance of the rabbit's septum as a relay station between the midbrain and the hippocampus. The control of hippocampal arousal by septal cells. Electroencephalog. Clin. Neurophysiol. 14: 202-211.

Ranck, J. B., Jr. (1973) Studies on single neurons in dorsal hippocampal formation and septum in unrestrained rats. Exp. Neurol. 41;461555.

Schwartzkroin, P. A., and L. H. Mathers (1978) Physiological and morphological identification of a nonpyramidal hippocampal cell type. Brain Res. 157: 1-10.

Sinclair, B., M. Seto, and B. Bland (1982) Theta cells in Ca 1 and detate layers of hippocampal formation: Relations to slow-wave activity and motor behavior in the freely moving rabbit. J. Neurophysiol. 48 . 214-225.

Stewart, M., and S. Fox (1989) Two populations of rhythmically bursting neurons in the rat medial septum. J. Neurophysiol. 61:982-993.

Thompson, L. T., and P. J. Best (1989) Place cells and silent cells in the hippocampus of freely-behaving rats. J. Neurosci. 9(7):23822390. 